\title{
PENINGKATAN KINERJA PROTOKOL PEGASIS DENGAN PEMBAGIAN AREA DAN PEMBENTUKAN CHAIN SECARA ADAPTIF
}

\author{
Muhammad Riko Anshori Prasetya*1, Waskhito Wibisono ${ }^{2}$ \\ ${ }^{1,2}$ Intitut Teknologi Sepuluh November (ITS)

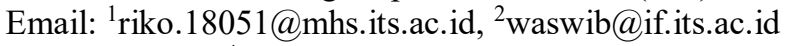 \\ ${ }^{*}$ Penulis Korespondensi
}

(Naskah masuk: 16 Juni 2020, diterima untuk diterbitkan: 26 November 2020)

\begin{abstract}
Abstrak
Wireless Sensor Networks (WSN) merupakan sebuah perangkat jaringan yang terdiri dari base station dan beberapa sensor node. WSN sendiri banyak digunakan dalam berbagai bidang seperti bidang industri, kesehatan, militer, dan pengelolaan bencana. Penggunaan WSN ini sendiri ditunjukkan untuk mendapatkan informasi terkait suhu, intensitas cahaya, getaran, panas, dan lain-lain. Saat mengumpulkan informasi, sensor node membutuhkan energi, namun sensor node memiliki energi yang terbatas. PEGASIS merupakan salah satu algoritma routing protokol dengan sistem chain-based yang berguna untuk menyelesaikan permasalahan tersebut. Namun dalam penggunaan berskala luas, protokol ini membutuhkan energi besar dalam melakukan transmisi data. Oleh karena itu, penelitian ini mengusulkan sebuah pengembangan PEGASIS, yaitu VCLUS-PEGASIS. VCLUS-PEGASIS memodifikasi area PEGASIS dengan membaginya menjadi beberapa grid secara vertikal. Selain itu, chain dalam satu grid akan diubah apabila terjadi transmisi yang panjang antara satu node dengan node tetangganya yang masih dalam satu area menggunakan algoritma K-Means. Hal tersebut bertujuan untuk meminimalisasi pengiriman energi setiap transmisi. Hasil pengujian menujukan jika protokol VCLUS-PEGASIS mampu untuk mempertahankan masa hidup node hingga 41,2\% lebih lama dari PEGASIS asli dan mampu untuk menghemat penggunaan energi hingga 4,58 \% daripada PEGASIS asli.
\end{abstract}

Kata kunci: Efesiensi Energi, Klaster, Sistem Rantai, Jaringan Sensor Nirkabel, PEGASIS

\section{THE ENHANCEMENT OF PEGASIS PROTOCOL PERFORMANCE BY ADAPTIVE AREA DISTRIBUTION AND CHAIN FORMATION}

\begin{abstract}
Wireless Sensor Networks (WSN) is a network device consisting of a base station and several sensor nodes. WSN is widely used in various fields such as industry, healthcare, military, and disaster management. The purpose of WSN is to obtain information related to temperature, vibration, heat, and so forth. Nevertheless, the sensor nodes have energy limitations. PEGASIS is one of the routing protocols with a chain-based system that is useful for solving these problems. However, this protocol requires a lot of energy while transmitting data in wide-scale use. This research proposes the development of PEGASIS, namely VCLUS-PEGASIS. VCLUS-PEGASIS modifies the area of PEGASIS by dividing it into vertical grids. Also, the chain in one grid will be changed if there is a long transmission between one node and its neighbor nodes that are still in one area. It aims to minimize the energy delivery of each transmission using the K-Means algorithm. The test result shows that the VCLUS-PEGASIS protocol is able to maintain the life span of nodes until 41,2\% longer than the standard PEGASIS and decrease the energy transmission until 4,58\% from the standard PEGASIS.
\end{abstract}

Keywords: Energy Efficiency, Cluster, Chain Based, Wireless Sensor Network, PEGASIS

\section{PENDAHULUAN}

Kemajuan teknologi di bidang Micro Electro Mechanical System (MEMS) mendorong peningkatan penggunaan dari Wireless Sensor Network (WSN). Teknologi WSN menggunakan sebuah perangkat komputer dengan ukuran yang kecil (sensor node) dan teknologi jaringan berbasis nirkabel yang terdiri dari sebuah Base Station (BS) dan gabungan dari banyak sensor node dalam suatu area tertentu yang berguna untuk memantau suhu, intensitas cahaya, getaran, panas, dan lain-lain pada suatu sistem atau lingkungan yang didukung dengan perangkat cerdas dan dikontrol secara aktual untuk di proses menjadi sebuah data yang digunakan untuk mendukung kegiatan manusia dalam melakukan 
pengamatan di berbagai macam bidang kegiatan. (Warrier \& Kumar, 2016)(Astuti \& Wibisono, 2017) (Somauroo \& Bassoo, 2019)(Arioua et al., 2016). Saat ini, teknologi WSN mendapat perhatian besar dengan digunakannya aplikasi WSN didalam berbagai bidang seperti bidang industri, kesehatan, militer, dan pengelolaan bencana (Sunil Kumar Singh, Kumar \& Jyoti Prakash Singh, 2017)(Wang et al., 2018).

Sensor node dalam WSN memakai baterai sebagai sumber tenaganya dan biasanya disebarkan dalam lingkungan yang sulit dan ekstrim sehingga sulit untuk dilakukan pengisian ulang maupun pergantian sensor node ketika energinya habis sementara sensor node sendiri memiliki kapasitas dan daya yang sangat terbatas (Wang et al., 2018)(Rana, Vhatkar \& Mohommad Atique, 2015)(Khan et al., 2015)(Fallo, Wibisono \& Kun Nursyaful Priyo Pamungkas, 2019). Oleh karena itu, cara untuk memperpanjang masa hidup dan juga untuk mengurangi konsumsi energi dari sensor node ini masalah yang sangat penting dalam bidang WSN (Ramluckun \& Bassoo, 2018)(Li, 2016).

Salah satu algoritma untuk meningkatkan masa hidup dan energi pada WSN yaitu PEGASIS (PowerEfficient Gathering in Sensor Information Systems) (Vhatkar, Shaikh \& Atique, 2017). PEGASIS sendiri merupakan sebuah protokol berbasis chain yang diklasifikasikan sebagai hierarchical protokol yang merupakan peningkatan dari LEACH protokol (Prajapat \& Barwar, 2018). Prokol PEGASIS menciptakan chain dari sensor node yang ada sehingga setiap sensor node dapat menerima dan mengirimkan data ke sensor node tetangga terdekatnya (Mishra \& Samantara, 2016). Chain sendiri terbentuk dengan menggunakan algoritma greedy (Rana, Vhatkar \& Mohommad Atique, 2015). Selain itu, pada salah satu dari sensor node didalam chain akan menjadi sebuah leader dengan tugas utama untuk mengirimkan data langsung ke BS (Prajapat \& Barwar, 2018).

Pada algoritma PEGASIS, banyak protokol yang berbeda yang dikembangkan untuk mengurangi jumlah energi dan menambah masa hidup jaringan pada PEGASIS. Beberapa penelitian sebelumnya telah dilakukan untuk mengurangi penggunaan energi dan juga meningkatkan masa hidup dari protokol PEGASIS seperti dalam penelitian (Ramluckun \& Bassoo, 2018) yang idenya adalah membangun clustering berdasarkan titik koordinat $\mathrm{x}$ dari nodes yang dinamakan PEG-ACO Vertical Clustering dan membangun clustering berdasarkan koordinat y dari nodes yang dinamakan PEG-ACO Horizontal Clustering. Chain sendiri dibuat pada setiap clustering dan mengadopsi transmisi yang multihop untuk menuju ke BS. CH pada setiap chain sendiri ditentukan berdasarkan perbandingan antara energi dan juga jarak.

Penelitian berikutnya (Huang, Yan \& Lin, 2012) mengusulkan metode berbasis grid-chain (EEGDG).
Metode ini membagi sensing area menjadi beberapa sub area agar dapat mengurangi jarak antar chain pada area sensing, dan menyeimbangkan konsumsi energi pada setiap node. Selain itu, protokol ini juga menggabungkan konsep cluster untuk memilih satu node di setiap area untuk melakukan proses pengumpulan dan sensing data. EEGDG mampu untuk memperpanjang masa hidup node dan mengurangi penggunaan energi dalam lingkungan skala besar

Penelitian (Sen, Bing \& Liangrui, 2011) mengembangkan PEGASIS dengan cara mengadopsi cara baru untuk menyederhanakan pembuatan chain pada saat proses konstruksi dengan mempertimbangkan chain yang panjang. Saat pemilihin leader pada protokol ini menggunakan metode pembobotan yang mempertimbangkan energi node dan jarak antara node dan BS sebagai parameternya. Penelitian ini sendiri berhasil mencatatkan energi yang lebih efesien dan memperpanjang masa hidup node.

Pada penelitian (Marhoon, Mahmuddin \& Nor, 2016) melakukan penelitian yang diberi nama PEGASIS-CC-DCF untuk meningkatkan network lifetime dengan menggunakan konsep formasi chain yang dinamis. Skema pada protokol ini sendiri memilih leader yang memikili energi sisa yang paling banyak yang digunakan sebagi penguhubung antar chain pada setiap level cluster. Hasil pada penelitian ini sendiri menujukan jika metode mampu meningkatkan network lifetime dari sensor node yang ada.

Dari beberapa penelitian yang telah dibahas memperlihatkan jika PEGASIS sendiri masih memiliki beberapa kelemahan seperti; semakin panjang chain yang dibentuk maka akan semakin besar energi untuk melakukan transmisi datanya. Oleh karena itu dalam penelitian ini akan diusulkan sebuah pengembangan dari PEGASIS yang dinamakan VCLUS-PEGASIS untuk mengatasi kekurangan tersebut dengan cara memodifikasi area pada PEGASIS dengan membaginya menjadi beberapa grid dengan bentuk vertikal. Selain itu, chain dalam satu grid akan diubah apabila terjadi transmisi yang panjang antara satu node dengan node tetangganya dalam satu area serta menambahkan leader baru pada setiap grid yang ada. Pengembangan dari PEGASIS ini diharapkan mampu untuk meningkatkan masa hidup dari sensor node dan juga mampu untuk mengurangi pemakaian energi saat melakukan transmisi data.

\section{METODE PENELITIAN}

Alur tahapan perancangan strategi untuk melakukan modifikasi pada PEGASIS dapat dilihat pada Gambar 1. Secara seluruhan, tahapan dalam pembentukan VCLUS-PEGASIS sendiri dibagi menjadi 3 fase. Adapun fase VCLUS-PEGASIS yaitu: (1) fase pembagian area dalam bentuk vertikal, (2) fase pembentukan chain, (3) fase pembentukan 
leader. Dalam setiap fase yang dilakukan akan dibahas dengan detail pada sub-bab sebagai berikut:

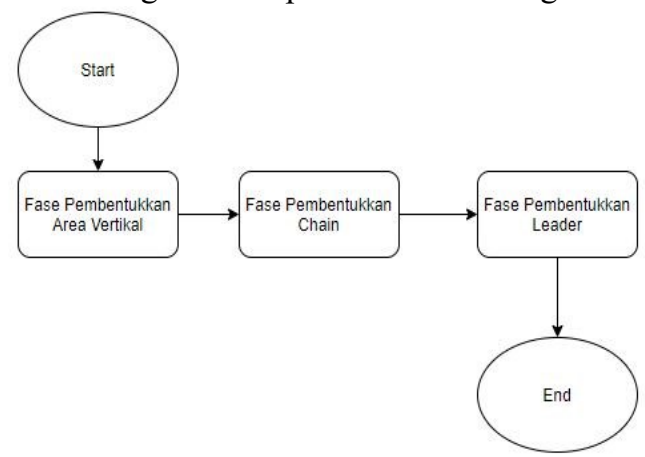

Gambar 1. Alur Perancangan VCLUS Pegasis

\subsection{Fase Pembagian Area Vertikal}

Tujuan utama pada fase ini adalahh membagi area sensing menjadi beberapa grid yang lebih kecil dengan tujuan untuk memperkecil energi pada saat melakukan transmisi dengan cara membagi area itu menjadi sama rata berdasarkan koordinat dari lebar node nya $(\mathrm{y})$. Untuk area $\left(\mathrm{A}^{*} \mathrm{~A}\right) \mathrm{m}^{2}$, ukuran area dalam satu grid akan $\left(\mathrm{A}^{*} \mathrm{~A} / \mathrm{k}\right) \mathrm{m}^{2}$ dimana $\mathrm{k}$ sendiri adalah jumlah dari grid yang diinginkan (Ramluckun \& Bassoo, 2018). Dalam setiap masing-masing grid sendiri akan dibentuk chain. Adapun pembagian grid dalam satu area ini dapat dilihat pada Gambar 2.

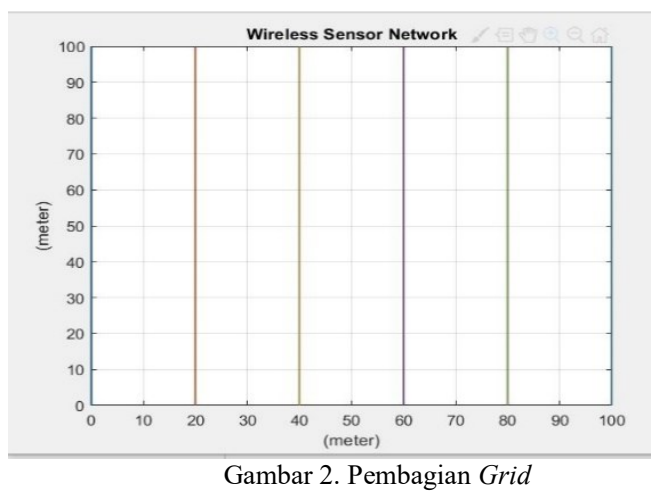

\subsection{Fase Pembentukan Chain}

Dalam fase ini, node dalam setiap area akan saling menghubungkan untuk membentuk sebuah chain. Modifikasi pada tahap ini dapat dilihat pada flowchart di Gambar 3.

Pada penelitian ini, setelah chain awal terbentuk, seluruh jarak antara satu node dengan node tetangganya pada satu grid tadi akan dihitung. Untuk menghitung jarak antara setiap node dengan node tetangganya digunakan rumus Euclidean Distance dengan menggunakan persamaan (1)(Rizaldi, Kurniawati \& Angkoso, 2018). Lalu setelah didapat jarak antar node dengan node tetangganya tadi, maka jarak tadi akan ditotalkan lalu dihitung nilai rataratanya. Nilai rata-rata ini nantinya akan dikalikan tiga dan nilai tersebut akan digunaan sebagai nilai batas (threshold) sebagai jarak maksimal suatu node dengan node tetangganya. Threshold sendiri dapat dilihat pada persamaan (2). Apabila node pada suatu grid tadi memiliki jarak yang melebihi nilai threshold, maka akan dilakukan pembuatan chain baru pada grid tersebut. Adapun pembuatan chain baru pada setiap node dapat dilihat pada Gambar 4 .

$j=\sqrt{\left(x_{2}-x_{1}\right)^{2}+\left(z_{2}-z_{1}\right)^{2}}$

dimana $j$ adalah jarak, $x_{2}$ adalah latitude $x_{2}$ dari node awal, $z_{2}$ adalah longitude $z_{2}$ dari node awal, $x_{1}$ adalah latitude $x_{1}$ ke node tujuan, $z_{1}$ adalah longitude $z_{1}$ ke node tujuan.

$\gamma=\frac{j_{1}+j_{2}+j_{3}+j_{\ldots n}}{n} \times 3$

dimana $\gamma$ adalah threshold, $j$ adalah jarak, $n$ adalah jumlah node.

Seperti terlihat pada Gambar 4, terlihat pada grid 2 dan grid 3 jika ada sebuah node yang memiliki jarak dengan tetangganya yang melebihi nilai threshold. Maka pada masing-masing grid tersebut akan dilakukan pembuatan chain baru yang dibagi dengan menggunakan algoritma K-Means. Cara pembentukan chain yang dilakukan dengan menggunakan algoritma K-mean, pembentukan ini dimulai dengan kelompok pertama yang dibentuk berdasarkan centroid yang dipilih secara acak yang digunakan sebagai titik awal setiap cluster, lalu dilakukan penghitungan ulang hingga menemukan nilai optimal posisi centroid. Setelah centroid telah stabil, chain baru akan terbentuk dalam satu grid. Sedangkan pada grid lain yang jarak node dengan node tetangganya tidak melebihi dari nilai threshold maka tidak terjadi perubahan pada grid tersebut. Adapun pembentukkan chain baru tersebut terlihat pada Gambar 5.

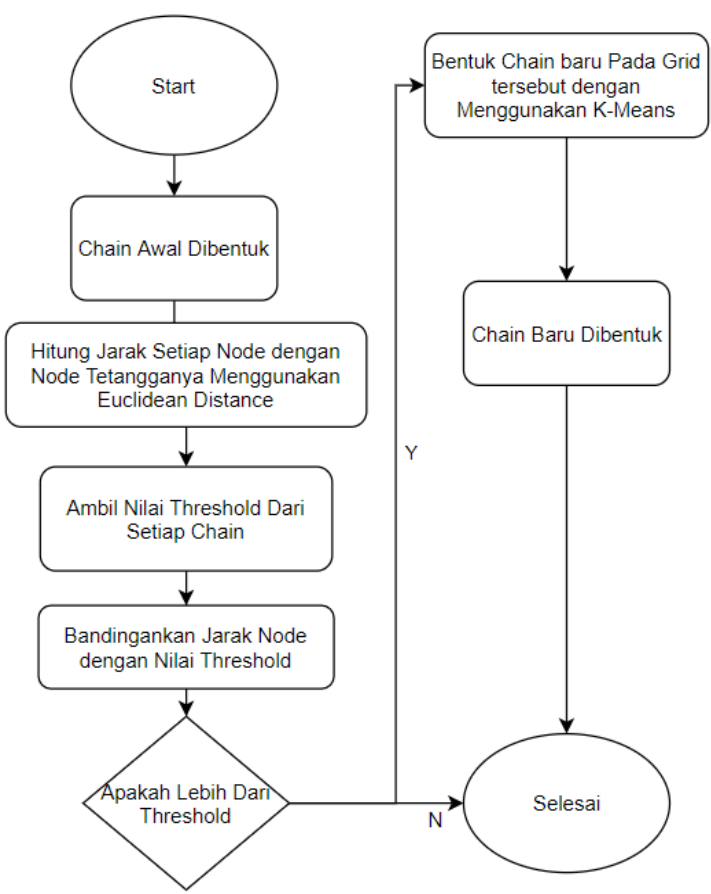

Gambar 3. Alur Fase Pembentukan Chain pada VCLUSPEGASIS 


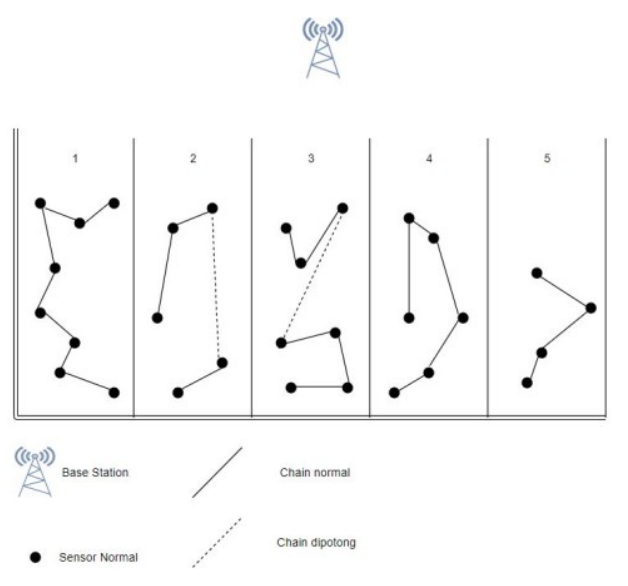

Gambar 4. Skenario Pembentukkan Chain

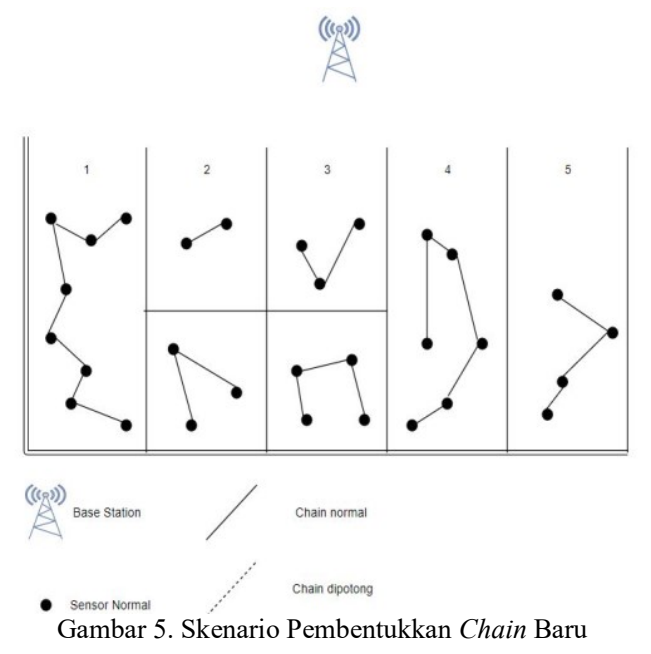

\subsection{Fase Pembentukan Leader}

Pembentukan leader di dalam penelitian ini sendiri akan dibentuk pada setiap area yang ada. Leader pada setiap area sendiri akan dipilih secara acak dan akan berganti pada setiap putaran. Leader sendiri memiliki fungsi sebagai node yang mengumpulkan semua data lalu mengirimkannya ke BS. Ketika leader node dipilih dan memberitahukan ke BS jika node tersebut adalah leader, setiap node pada chain akan melakukan transmit data dan menerima gabungan data hingga ke leader (Lindsey \& Raghavendra, 2002). Adapun skenario 2 round awal dalam pencarian leader dari fase ini dapat dilihat pada Gambar 6 dan Gambar 7.

\subsection{Radio dan Model Energi}

Radio dan model energi yang digunakan pada penelitian ini pada setiap transmisinya akan dihitung menggunakan persamaan yang sama dengan beberapa penelitian seperti(Prajapat \& Barwar, 2018)(Mishra \& Samantara, 2016)(Marhoon, Mahmuddin \& Nor, 2016). Dapat terlihat pada Gambar 8 dapat dilihat model radio yang digunakan dalam perhitungan energi yang digunakan.
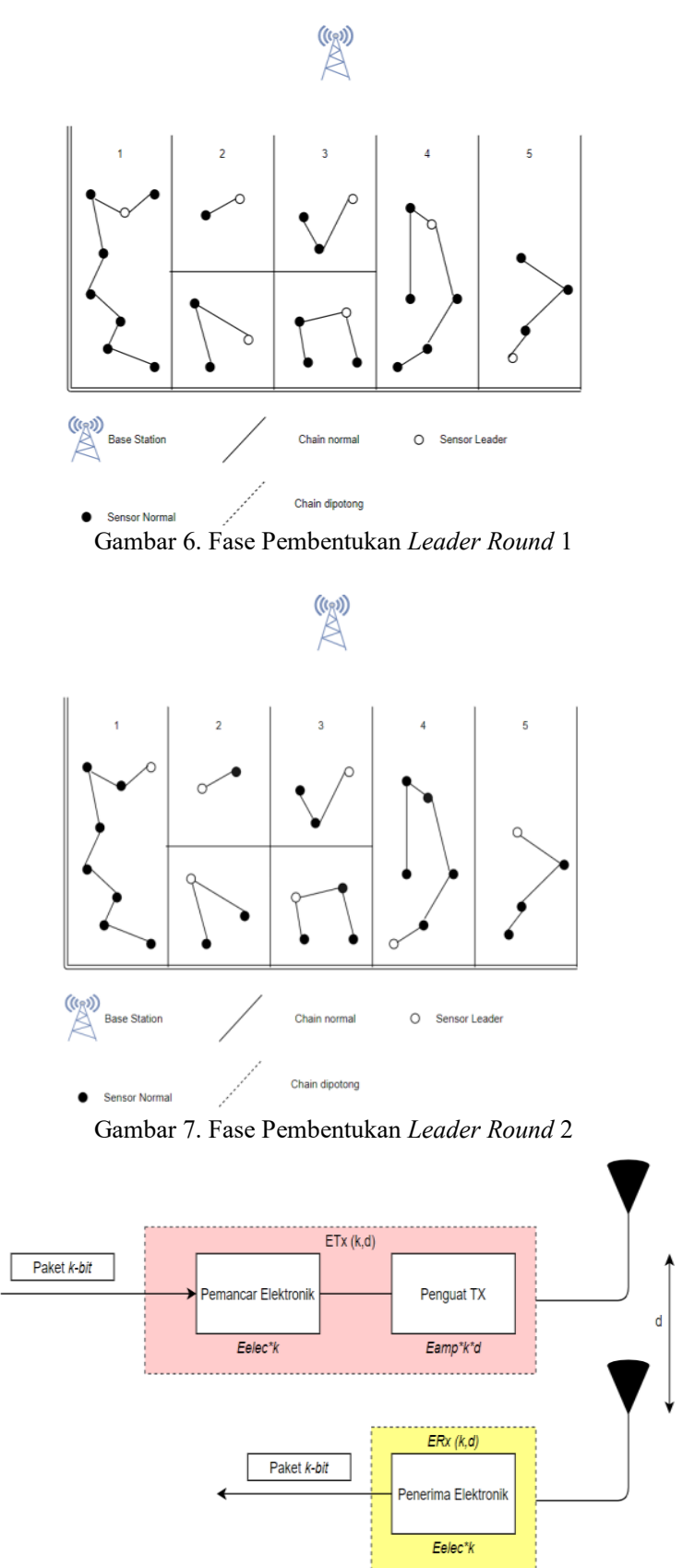

Gambar 8. Radio Model (Lindsey \& Raghavendra, 2002)

Dalam penggunaan energi, energi yang paling digunakan terletak pada saat transmisi dan penerimaan data. Pada saat melakukan transmisi, ada dua buah cara dalam perhitungan disipasi energi didalam jaringan yaitu dengan model free space dan model multipath. Dalam melakukan penstransmisian paket data sebesar $k$-bit dengan jarak $d$ meter, energi yang dibutuhkan radio dapat dihitung dengan menggunakan persamaan $(3)(4)(5)$ berikut:

$$
\begin{aligned}
& E_{T X}=E_{T X-e l e c}(k)+E_{T X-a m p}(k, d) \\
& k * E_{\text {elec }}+k * \varepsilon_{f S} * d^{2} \quad \text { if } d<d_{0} \\
& k * E_{\text {elec }}+k * \varepsilon_{m p} * d^{4} \quad \text { if } d \geq d_{0}
\end{aligned}
$$


Dimana $E_{T X}$ adalah energi yang diperlukan ketika proses transmisi dilakukan, $E_{\text {elec }}$ merupakan energi yang dibutuhkan untuk melakukan proses sebelum packet data unit ditransmisikan, $d$ adalah jarak antara perangkat transmisi dan penerima, $d_{0}$ merupakan nilai threshold untuk menentukan apakah akan memakai model free space atau multipath, $\varepsilon_{f s}$ merupakan dispisasi energi per bit yang digunakan amplifier pada mode free space dan $\varepsilon_{m p}$ yang digunakan amplifier pada model multipath.

Pada perangkat penerima data sendiri, energi yang digunakan saat menerima data sebesar k-bit packet data unit, maka energi yang dibutuhkan terlihat pada persamaan (5) berikut:

$$
E_{r x}^{(k)}=E_{r x-e l e c}^{(k)}=k * E_{\text {elec }}
$$

Dimana $E_{r x^{(k)}}$ energi yang dibutuhkan oleh penerima untuk menerima sejumlah bit packet data unit setiap data k-bit.

Terakhir pada saat perangkat menerima, akan ada penggabungan data pada data di setiap node pada chain. Adapun energi yang dikeluarkan pada saat penggabungan data ini dapat dilihat pada persamaan (6) berikut:

$$
E_{D A-t o t}=s * k * E_{d a}
$$

Dimana $E_{d a}$ adalah energi per bit yang dikeluarkan pada saat melakukan penggabungan data dan $s$ adalah jumlah dari sinyal yang digabungkan.

\section{HASIL DAN PEMBAHASAN}

Pada bagian hasil ini akan dibahas tentang hasil simulasi dari protokol VCLUS-PEGASIS yang dibandingkan dengan protokol PEGASIS Parameter data yang bersifat tetap diperlukan untuk melakukan uji coba berdasarkan pada protokol PEGASIS (Lindsey \& Raghavendra, 2002). Uji coba sendiri dilakukan dengan menggunakan MATLAB dengan penempatan sensor node secara acak dengan jumlah kerapatan 200 node dalam area simulasi sepanjang $100 * 100 \mathrm{~m}^{2}$ dan base station yang diletakkan di tengah pada area 50*50. Skenario pengujian dilakukan dengan energi awal dari setiap node pada simulasi ini sebanyak 2 Joule dengan energi yang dibutuhkan untuk melakukan transmisi sebanyak 50 $\mathrm{nJ} /$ bit.

Pengujian sendiri akan dihitung hingga semua energi pada node habis. Adapun parameter uji coba yang dilakukan dapat dilihat pada Tabel 1. Pada simulasi yang dilakukan menggunakan parameter diatas didapatkan area simulasi yang terlihat pada Gambar 9.

Untuk melakukan evaluasi kinerja pada protokol yang diajukan maka digunakan evaluasi berdasarkan persentase hidup node (Alive Node in Network) yang dihitung berdasarkan FND (First Node Die), HND (Half Node Die), serta LND (Last Node Die) dan average consumption energy per transmision dan dibandingkan dengan evaluasi kinerja pada protokol PEGASIS. Detail dari parameter evaluasi sendiri dapat dilihat pada Tabel 2 .

Tabel 1. Tabel Parameter Uji Coba

\begin{tabular}{ll}
\hline Parameter & Kapasitas \\
\hline Area Simulasi & $100 * 100$ \\
Jumlah Grid & 5 \\
Jumlah node & 200 node \\
Energi awal Node $\left(\mathrm{E}_{\text {init }}\right)$ & $2 \mathrm{~J}$ \\
Pemancar Energi $\left(\mathrm{E}_{\text {elec }}\right)$ & $50 \mathrm{~nJ} / \mathrm{bit}$ \\
Base Station $(\mathrm{BS})$ & $50 * 50$ \\
\hline
\end{tabular}

\begin{tabular}{|c|c|}
\hline Parameter & Penjelasan \\
\hline $\begin{array}{l}\text { Persentase Hidup Node (Alive } \\
\text { Node in Network) }\end{array}$ & $\begin{array}{l}\text { Rentang waktu dari sensor } \\
\text { node pertama kali } \\
\text { disebarkan hingga semua } \\
\text { sensor } \text { node mati }\end{array}$ \\
\hline $\begin{array}{l}\text { Average consumption Energy } \\
\text { per Transmission }\end{array}$ & $\begin{array}{l}\text { Rata-rata energi transmisi } \\
\text { setiap round dari sensor } \\
\text { node pertama kali } \\
\text { disebarkan hingga sensor } \\
\text { node pertama mati }\end{array}$ \\
\hline
\end{tabular}

Tabel 2. Tabel Evaluasi Uji Coba

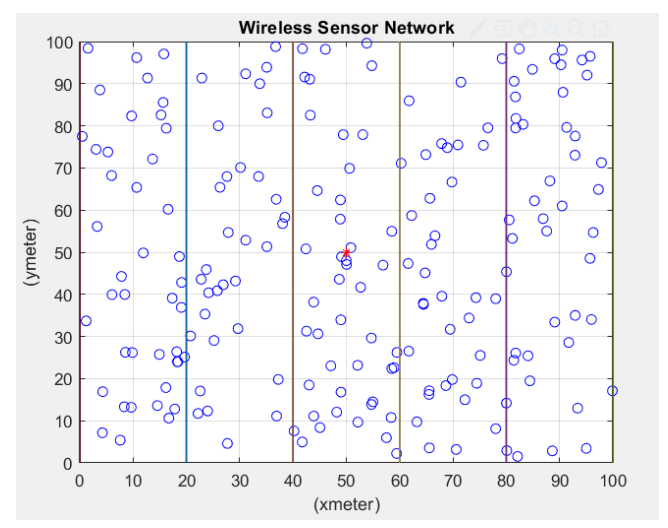

Gambar 9. Area Simulasi 200 node

\subsection{Persentase Hidup Node}

Persentase hidup node sendiri merupakan rentang waktu antara node pertama disebarkan hingga node terakhir mati. Dalam analisa tentang persentase hidup node diukur berdasarkan beberapa kriteria utama yaitu berapa round yang dibutuhkan dalam area simulasi tersebut ketika node pertama mati (First Node Die), lalu pada round berapa 50\% node mati (Half Node Die), dan terakhir pada round berapa seluruh node mati (Marhoon, Mahmuddin \& Nor, 2016). Hasil uji coba sendiri ditunjukkan pada Gambar 10.

Terlihat pada Gambar 10, protokol VCLUSPEGASIS memiliki jumlah persentase hidup node yang lebih baik daripada PEGASIS baik dari kerapatan 100 node maupun pada kerapatan 200 node. VCLUS-PEGASIS memiliki jumlah node hidup yang lebih lama dari pada PEGASIS. Berdasarkan hasil uji coba, selisih perbandingan dari persentase hidup node pada VCLUS-PEGASIS dan PEGASIS ditampilkan pada Tabel 3. 
FND pada VCLUS-PEGASIS mendapatkan selisih transmisi sebanyak $86,49 \%$ lebih baik dari pada PEGASIS asli. HND pada VCLUS-PEGASIS juga mendapatkan hasil selisih lebih baik dari pada PEGASIS asli dimana terlihat node mampu bertahan $3,87 \%$ round lebih lama dari PEGASIS asli dan terakhir pada LND terlihat jika VCLUS-PEGASIS mampu untuk bertahan $41,2 \%$ lebih baik dari pada PEGASIS asli. Hasil ini memperlihatkan jika teknik teknik pembagian area dan pembentukan chain secara adaptif pada protokol VCLUS-PEGASIS dapat meningkatkan persentase hidup node lebih banyak dari pada protokol PEGASIS.

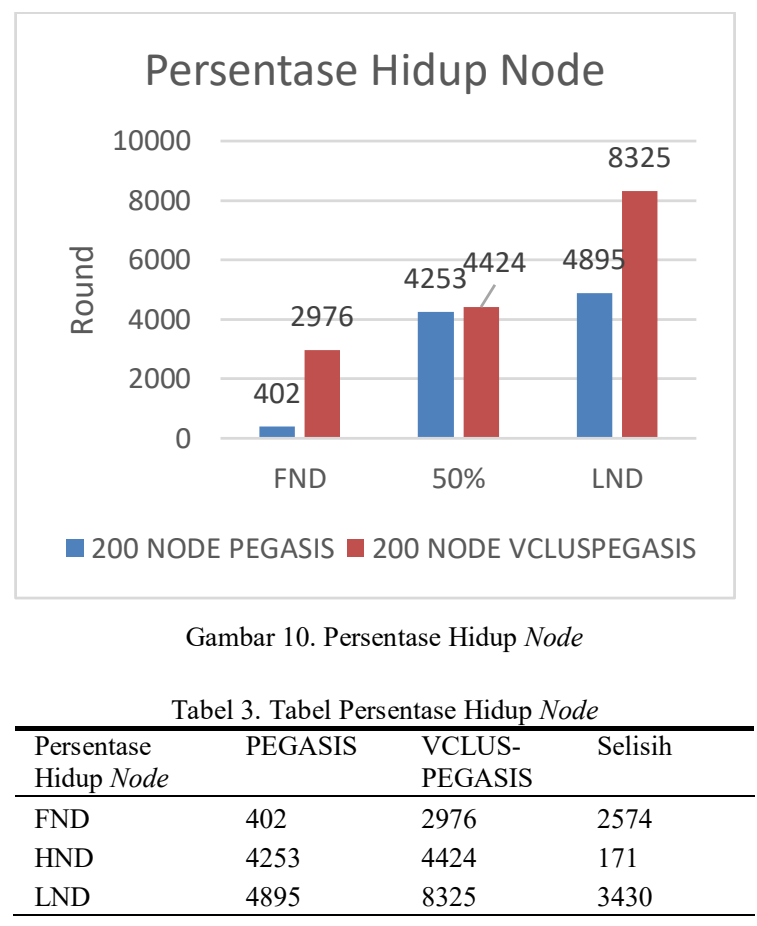

\subsection{Average Energy Consumed by A Node}

Dalam WSN, selain dari pentingnya persentase hidup node sebagai evaluasi pertama dalam pengukuran kinerja dari WSN, diperlukan juga pengukuran rata-rata energi yang diperlukan node dalam melakukan transmisi ke base station hingga node pertama mati (Average Energy Consumed by $A$ Node)(Marhoon, Mahmuddin \& Nor, 2016). Hasil uji coba sendiri ditunjukkan pada Gambar 11.

Dapat dilihat pada Tabel 3 perbandingan ratarata energi yang diperlukan node pada PEGASIS dan VCLUS-PEGASIS didapat jika VCLUS-PEGASIS memiliki transmisi dengan rata-rata energi yang lebih rendah dari pada PEGASIS asli. Terlihat pada Tabel 4 jika selisih pada kedua teknik ini adalah 0,0000023 joule yang berarti VCLUS-PEGASIS mentransmisikan 4,58\% energi yang lebih rendah dari pada PEGASIS asli.

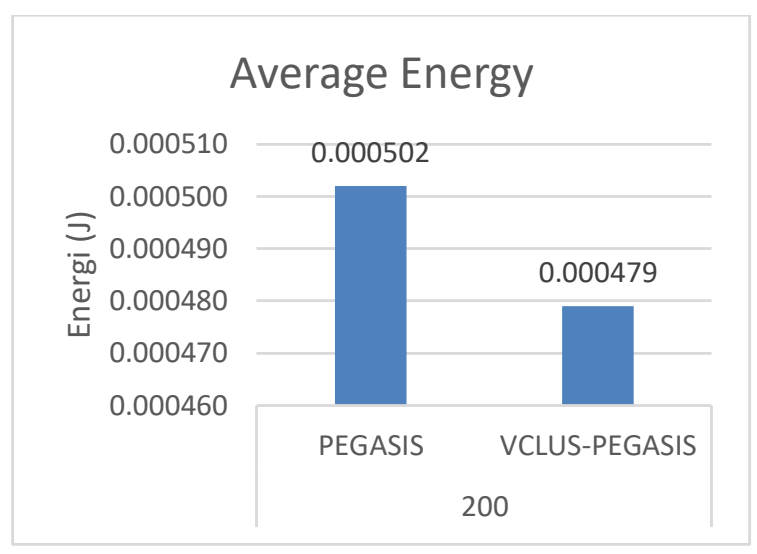

Gambar 11. Average Energy Consumed by A Node

Walaupun dapat disimpulkan jika VCLUSPEGASIS memiliki nilai rata-rata energi yang lebih rendah dari pada PEGASIS namun selisihnya tidak terlalu jauh. Nilai yang tidak terlalu jauh berbeda ini disebabkan karena pengaruh grid yang lebih jauh dari BS dimana semakin jauh grid dari $B S$ menyebabkan energi yang dikeluarkan akan semakin besar.

Tabel 4. Average Energy Consumed by A Node

\begin{tabular}{lcll}
\hline $\begin{array}{l}\text { Persentase } \\
\text { Hidup Node }\end{array}$ & PEGASIS & $\begin{array}{l}\text { VCLUS- } \\
\text { PEGASIS }\end{array}$ & Selisih \\
\hline Energi & 0.000502 & 0.000479 & 0.000023 \\
\hline
\end{tabular}

\section{KESIMPULAN}

Protokol VCLUS-PEGASIS merupakan modifikasi dari PEGASIS dengan cara melakukan pembagian area WSN menjadi beberapa grid dalam bentuk vertikal dengan luas area sensing yang sama dan melakukan pembentukan chain baru pada setiap grid dengan menggunakan algoritma K-Means jika ada node di dalam chain yang mempunyai jarak yang melebihi nilai threshold. Berdasarkan uji coba yang dilakukan, protokol VCLUS-PEGASIS mampu meningkatkan persentase hidup node hingga 41,2\% dan mampu untuk menghemat energi sebanyak 4,58\% daripada PEGASIS asli. Sehingga dapat disimpulkan jika VCLUS-PEGASIS mampu untuk mempertahankan masa hidup node dan menurunkan transmisi energi daripada PEGASIS.

\section{DAFTAR PUSTAKA}

ARIOUA, M. ET AL. (2016) 'Multi-hop cluster based routing approach for wireless sensor networks', Procedia - Procedia Computer Science. Elsevier Masson SAS, 83(Ant), pp. 584-591. doi: 10.1016/j.procs.2016.04.277.

ASTUTI, L. D. \& WIBISONO, W. (2017) 'Peningkatan Network Lifetime Pada Wireless Sensor Network Mmenggunakan Clustered Shortest Geopath Routing (CSGP) Protocol', Jurnal Teknologi Informasi dan Ilmu Komputer, 4(3), pp. 148-153.

CHEN, Y. \& LIN, J. (2012) 'Energy efficiency analysis of a chain-based scheme via intra- 
grid for wireless sensor networks', Computer Communications. Elsevier B.V., 35(4), pp. 507-516. doi: 10.1016/j.comcom.2011.12.002.

FALLO, K., WIBISONO, W. \& KUN NURSYAFUL PRIYO PAMUNGKAS (2019) 'Pengembangan mekanisme grid based clustering untuk peningkatan kinerja LEACH pada lingkungan Wireless Sensor Network Development of a grid-based clustering mechanism to improve LEACH performance in the Wireless Sensor Network environment', Jurnal Ilmiah Teknologi Sistem Informasi, 5(34), pp. 152 161.

HUANG, Y., YAN, L.-C. \& LIN, J. (2012) 'An Efficient Energy Data Gathering Based on Grid- Chain for Wireless Sensor Networks', in 4th International Conference on Awareness Science and Technology. Seoul, pp. 78-82. doi: 10.1109/iCAwST.2012.6469593.

KHAN, A. R. ET AL. (2015) 'Comparative Study of WSN Protocols', in 2015 Third International Conference on Image Infonnation Processing Comparative. Waknaghat: IEEE, pp. 422-427. doi: 10.1109/ICIIP.2015.7414810.

LI, L. (2016) 'Data Aggregation in Wireless Sensor Networks', International Journal of Online and Biomedical Engineering, 12(11), pp. 28-33. Available at: https://doi.org/10.3991/ijoe.v12i11.6233.

LINDSEY, S. \& RAGHAVENDRA, C. S. (2002) 'PEGASIS: Power-efficient gathering in sensor information systems', in IEEE Aerospace Conference Proceedings. Big Sky, pp. 1125-1130. doi: 10.1109/AERO.2002.1035242.

MARHOON, H. A., MAHMUDDIN, M. \& NOR, S. A. (2016) 'DCBRP : a deterministic chain based routing protocol for wireless sensor networks', SpringerPlus. Springer International Publishing, pp. 1-21. doi: 10.1186/s40064-016-3704-1.

MISHRA, A. K. \& SAMANTARA, M. K. (2016) 'A Dynamic Energy-Efficient Chain Formation Scheme for PEGASIS in Wireless Sensor Networks', in 2016 International Conference on Computational Intelligence and Networks. Bhubaneswar: IEEE, pp. 4146. doi: 10.1109/CINE.2016.15.

PRAJAPAT, M. \& BARWAR, N. C. (2018) 'Performance Analysis of Energy Dissipation in WSNs Using Multi-Chain Performance Analysis of Energy Dissipation in WSNs Using Multi-Chain PEGASIS', International Journal of Computer Science and Information Technologies, 5(4), pp. 8033-8036.

RAMLUCKUN, N. \& BASSOO, V. (2018) 'Energyefficient chain-cluster based intelligent routing technique for Wireless Sensor Networks Applied Computing and Informatics Energy-efficient chain-cluster based intelligent routing technique for Wireless Sensor Networks', Applied Computing and Informatics. King Saud University, (April). doi: 10.1016/j.aci.2018.02.004

RANA, J., VHATKAR, S. \& MOHOMMAD ATIQUE (2015) 'Comparative Study of PEGASIS and PDCH Protocols in Wireless Sensor Network', in International Conference and Workshop on Emerging Trends in Technology (ICWET), pp. 13-18.

RIZALDI, R., KURNIAWATI, A. \& ANGKOSO, C. V. (2018) 'Implementasi Metode Euclidean Distance untuk Rekomendasi Ukuran Pakaian pada Aplikasi Ruang Ganti Virtual', Jurnal Teknologi Informasi dan Ilmu Komputer, 5(2), p. 129. doi: 10.25126/jtiik.201852592.

SEN, F., BING, Q. \& LIANGRUI, T. (2011) 'An Improved Energy-Efficient PEGASISBased Protocol in Wireless Sensor Networks', in 2011 Eighth International Conference on Fuzzy Systems and Knowledge Discovery (FSKD). Shanghai: IEEE, pp. 2230-2233. doi: 10.1109/FSKD.2011.6020058.

SOMAUROO, A. \& BASSOO, V. (2019) 'Energyefficient genetic algorithm variants of PEGASIS for 3D Wireless Sensor Networks', Applied Computing and Informatics. King Saud University. doi: 10.1016/j.aci.2019.07.002.

SUNIL KUMAR SINGH, KUMAR, P. \& JYOTI PRAKASH SINGH (2017) 'A Survey on Successors of LEACH Protocol', IEEE Access, 5, pp. 4298-4328. doi: 10.1109/ACCESS.2017.2666082.

VHATKAR, S., SHAIKH, S. \& ATIQUE, M. (2017) 'Performance Analysis of Equalized and Double Cluster Head Selection Method in Wireless Sensor Network', in 2017 Fourteenth International Conference on Wireless and Optical Communications Networks (WOCN). Mumbai: IEEE, pp. 15. doi: 10.1109/WOCN.2017.8065854.

WANG, J. ET AL. (2018) 'An Enhanced PEGASIS Algorithm with Mobile Sink Support for Wireless Sensor Networks', Wireless Communications and Mobile Computing, 2018, pp. 1-9. Available at: https://doi.org/10.1155/2018/9472075. 
1278 Jurnal Teknologi Informasi dan Ilmu Komputer (JTIIK), Vol. 7, No. 6, Desember 2020, hlm. 1271-1278

WARRIER, M. M. \& KUMAR, A. (2016) ‘An energy efficient approach for routing in wireless sensor networks', in Global Colloquium in Recent Advancement and Effectual Researches in Engineering, Science and Technology (RAEREST). The Author(s), pp. 520-527.

doi: 10.1016/j.protcy.2016.08.140. 